\title{
Anti-Diabetic Medications Do Not Influence Risk of Lung Cancer in Patients with Diabetes Mellitus: a Systematic Review and Meta-analysis
}

\author{
Shu-Ping Nie ${ }^{1,2}$, Hui Chen ${ }^{1,2}$, Mao-Qiang Zhuang ${ }^{3}$, Ming Lu ${ }^{1,2 *}$
}

\begin{abstract}
Objectives: Several preclinical and observational studies have shown that anti-diabetic medications (ADMs) may modify the risk of lung cancer. We performed a systematic review and meta-analysis evaluating the effect of metformin, sulfonylureas (SUs), thiazolidinediones (TZDs), and insulin on the risk of lung cancer in patients with diabetes mellitus (DM). Materials and Methods: We conducted a systematic search of Pubmed and Web of Science, up to August 20, 2013. We also searched the Conference Proceedings Citation Index (CPCI) and China National Knowledge Infrastructure (CNKI) for abstracts from major meetings. Fixed or random effect pooled measures were selected based on heterogeneity among studies, which was evaluated using $Q$ test and the $I^{2}$ of Higgins and Thompson. Meta-regression was used to explore the sources of between-study heterogeneity. Publication bias was analyzed by Begg's funnel plot and Egger's regression test. Associations were assessed by odds ratios (ORs) with 95\% confidence intervals (CIs). Results: A total of 15 studies (11 cohort, 4 case-control) were included in this meta-analysis. In observational studies no significant association between metformin $(\mathrm{n}=11$ studies; adjusted $O R=0.99,95 \%$ CI: 0.87-1.12), $\mathrm{SUs}$ ( $\mathrm{n}=5$ studies; adjusted $\mathrm{OR}=\mathbf{0 . 9 8 , 9 5 \%} \mathrm{CI}$ : 0.79-1.22), or TZDs $(n=7$ studies; adjusted OR=0.92,95\% CI: 0.75-1.13), insulin ( $n=6$ studies; adjusted OR=1.13,95\% CI: 0.79-1.62) use and risk of developing lung cancer was noted. There was considerable inherent heterogeneity between studies not explained by study design, setting, or location. Conclusions: Meta-analysis of existing studies does not support a protective or harmful association between ADMs use and risk of lung cancer in patients with DM. There was considerable heterogeneity across studies, and future, well-designed, prospective studies would be required for better understanding of any association.
\end{abstract}

Keywords: Anti-diabetic medications - diabetes mellitus patients - lung cancer risk - meta-analysis

Asian Pac J Cancer Prev, 15 (16), 6863-6869

\section{Introduction}

Lung cancer is one of the leading causes of cancer-related mortality worldwide and accounts for approximately $30 \%$ of cancer deaths in US (Jemal et al., 2010). Despite advances in early diagnosis and treatment modalities, prognosis remains poor; the five-year survival rate is only about $15 \%$ (Mulshine et al., 2005). Individuals at risk for developing lung cancer can be identified by clinical epidemiologic factors (Bach et al., 2003; Spitz et al., 2007; Cassidy et al., 2008; Tammemagi et al., 2011; Ding et al., 2013) and it has been well established that tobacco smoking is the most important cause of lung cancer, accounting for $85 \%-90 \%$ of all cases in the world (Ruano-Ravina et al., 2003; Tyczynski et al., 2003). The remaining cases were attributable to nonsmoking causes such as pulmonary tuberculosis, environmental exposure to radon and arsenic in drinking water in homes, occupational exposure to asbestos and other carcinogens, as well as family history of lung cancer (Lam et al., 2004;
Bruske-Hohlfeld, 2009; Gao et al., 2009; WU et al., 2011). When lung cancer is diagnosed, it is often in an advanced stage. Available treatment has a significant impact on outcomes, however, the overall success of treatment remains poor. Therefore, the prevention of lung cancer is of utmost importance and urgent efforts are needed to identify measures, including drug treatment that may be effective in reducing the lung cancer risk.

Diabetes mellitus (DM) is a metabolic disorder that is characterized by chronic hyperglycemia and aberrant carbohydrate, fat, and protein metabolism that result from defects in insulin secretion, insulin action, or both (Leone et al., 2014). It represents a major global health problem that has been recognized and treated for centuries. DM comprises two predominant subtypes, types- 1 and -2 that are characterized by different metabolic activities. Type 1 diabetes (5-10\% of all diabetics) is associated with the complete absence of endogenous insulin that is attributed to the autoimmune destruction of insulin secreting $\beta$-pancreatic cells and requires the

${ }^{1}$ Clinical Epidemiology Unit, Qilu Hospital of Shandong University, ${ }^{2}$ Department of Epidemiology and Health Statistics, School of Public Health, Shandong University, ${ }^{3}$ Shandong Center for Disease Control and Prevention, Jinan, China *For correspondence: lvming@sdu.edu.cn 
exogenous administration of insulin (Awoniyi et al., 2013). In contrast, type 2 diabetes ( $90 \%$ of all diabetics) is characterized by the long-term presence of hyperglycemia and hyperinsulinemia associated with insulin resistance in the peripheral tissues (Staimez et al., 2013; Zabetian et al., 2013).

Diabetes mellitus has been associated with a decreased risk of lung cancer in some (Rousseau et al., 2006; Ogunleye et al., 2009; Atchison et al., 2011) but not all studies (Hall et al., 2005; Ehrlich et al., 2010; Lai et al., 2012), a finding which may be explained by different smoking habits. Furthermore, it was reported that diabetic patients using metformin plus any other treatment had a lung cancer risk that was $37 \%$ lower than those not using the anti-diabetes drug (Hall et al., 2005).

Several preclinical in vitro and in vivo studies have shown that conventional anti-diabetic medications (ADMs) may modify the risk of multiple cancers. Metformin has been shown to have anti-neoplastic effects through both insulin-dependent and insulin independent mechanisms (Gallagher et al., 2011). By acting directly on cancer cells or on cells at risk for transformation, metformin can impair mitochondrial adenosine triphosphate (ATP) production, leading to the activation of liver kinase (AMPK) signaling, resulting in a decrease in protein synthesis and lipid synthesis via inhibition of mammalian target of rapamycin and fatty acid synthase, respectively (Smiechowski et al., 2013). Thiazolidinediones (TZDs) have been postulated to induce cell growth arrest and apoptosis and prevent cancer cell invasion (Okumura, 2010). TZDs suppress mitogen-activated protein kinase (MAPK) activation and the phosphorylation of peroxisome proliferator activatived receptors (PPAR), and in turn induce differentiation and growth repression. Sulfonylureas (SUs), on the other hand, by promoting insulin secretion, and insulin itself, can promote cell proliferation and cause carcinogenic effects (Bowker et al., 2006).

Epidemiological studies have shown that metformin and TZDs use among diabetic patients may be associated with lower risk of overall cancer incidence and mortality (Decensi et al., 2010; Noto et al., 2012; Soranna et al., 2012). On the other hand, insulin and insulin secretagogues are associated with higher cancer incidence and cancer related mortality (Bowker et al., 2006; Chang et al., 2012). In studies on risk of lung cancer, some studies suggest that metformin and TZDs may be chemopreventive in patients with DM (Govindarajan et al., 2007; Lai et al., 2012; Ruiter et al., 2012), whereas others show no beneficial effect (Bodmer et al., 2012; Mazzone et al., 2012). Likewise, some studies suggest that SUs and insulin may promote risk of lung cancer (Chang et al., 2012; Hsieh et al., 2012), whereas others show no harmful effects (Lai et al., 2012; Gu et al., 2013).

Hence, in order to understand this association better and evaluate its magnitude and the quality of the supporting evidence, we performed a systematic review and meta-analyses of observational studies that evaluated the effect of conventional ADMs (metformin, SUs, TZDs, and insulin) on the risk of developing lung cancer in patients with DM.

\section{Materials and Methods}

\section{Literature search}

A systematic literature search of pubmed, Web of Science databases was conducted by two study investigators, independently, for all relevant articles on the effect of anti-diabetic medications (ADMs) use on the risk of lung cancer from the first available year to August 20, 2013. The following keywords and/or corresponding MeSH terms were used: (Metformin or biguanides or hypoglycemic agents or sulfonylurea compounds or thiazolidinediones or insulin) and (cancer or carcinoma or neoplasms) and lung. The search was restricted to epidemiological studies conducted in humans. The title and abstract of studies identified in the search were reviewed by two authors independently to exclude the studies that did not answer the research question of interest. Moreover, the reference lists of the selected papers and the recent reviews were also screened for other potential articles that possibly have been missed in the initial search (references cited in the identified articles were searched manually). The most recent and complete publication was chosen if there were multiple publications for the same study.

When incomplete information was available, attempts were made to contact the corresponding authors of the studies for additional information.

\section{Selection criteria}

The inclusion criteria were as follows:

(1) evaluated and clearly defined exposure to any ADMs

(2) cohort studies, case-control or nested casecontrol studies

(3) reported crude or adjusted estimates of the association between exposure and outcome (that is, relative risk [RR], odds ratio[OR], hazard ratio[HR], and the corresponding $95 \%$ confidence interval $[\mathrm{CI}]$ ), or sufficient raw data to allow their calculation

(4) reported lung cancer incidence in patients with DM

(5) specifically mentioned that participants were affected by type 2 diabetes mellitus

\section{Data abstraction and quality assessment}

Data were independently abstracted onto a standardized form by two reviewers. The following data were collected from each study: name of the first author, year of publication, time period of study, country of the population studied, study design, information source for exposure ascertainment and outcome assessment, exposure vs. comparison, the fully adjusted hazard ratio (HR)/relative risk (RR)/odds ratio (OR) and their $95 \%$ confidence intervals (95\% CIs) were used as the common measure of associations. Conflicts in data abstraction were resolved by consensus, referring back to the original article. Quality assessment for included studies was performed using the Newcastle Ottawa scale (NOS) recommended by the Cochrane Non-Randomized Studies Methods Working Group (Wells et al., 2013). Data extraction and 
quality assessment were performed by two independent investigators. Any disagreement was settled by discussion.

\section{Statistical analysis}

The pooling method was adopted, as the inversevariance weighted mean of the logarithm of HR/RR/ OR (defined as summary RR (SRR)) with its $95 \% \mathrm{CI}$, to assess the strength of association between ADMs and the risk of lung cancer in diabetes mellitus. The $I^{2}$ of Higgins and Thompson was used to assess heterogeneity among studies. In the presence of substantial heterogeneity $\left(I^{2}>50 \%\right)$ (Higgins et al., 2003), the DerSimonian and Laird random effect model (REM) was adopted as the pooling method, otherwise, the fixed effect model (FEM) was used as the pooling method. Meta-regression was applied to detect the potentially important covariates exerting substantial impact on between-study heterogeneity. Sensitivity analysis was performed to validate the stability of outcomes by sequential removal of each individual study (Tobias, 1999). An individual study is suspected to excessively influence the point estimate if its omitted analysis lies outside the $95 \%$ CI of the combined analysis. The small-study effect in terms of publication bias was estimated using Egger's linear regression test (Egger et al., 1997). All reported probabilities ( $p$ values) were twosided, with $p<0.05$ considered statistically significant. All statistical analyses were performed with STATA version 11.1 (Stata, College Station, TX, USA).

\section{Results}

\section{Characteristics of studies}

Of the total 2595 unique studies identified using the search strategy, 15 (Govindarajan et al., 2007; Libby et al., 2009; Ferrara et al., 2011; Bodmer, 2012; Chang et al., 2012; Hsieh et al., 2012; Lai et al., 2012; Luo et al., 2012; Mazzone et al., 2012; Ruiter et al., 2012; van Staa et al., 2012; Gu et al., 2013; Kao et al., 2013; Smiechowski et al., 2013; Wang et al., 2013) studies fulfilled the inclusion criteria and were pooled in the meta-analysis (Figure 1). The characteristics of these studies are shown in Table

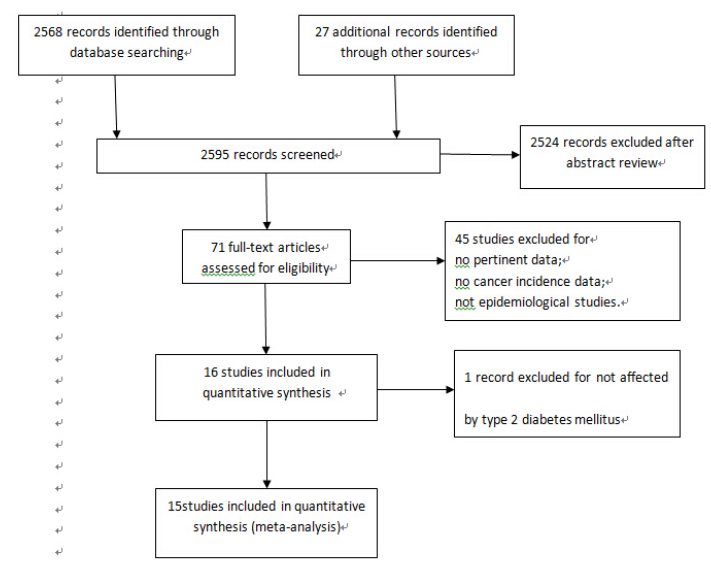

Figure 1. Flow Chart of Study Selection

\section{Table 1. Characteristics of Included Studies}

\begin{tabular}{|c|c|c|c|c|c|c|c|c|}
\hline $\begin{array}{l}1^{\text {st }} \text { author, } \\
\text { year }\end{array}$ & Design & $\begin{array}{l}\text { Location/ } \\
\text { Setting }\end{array}$ & Time period & $\begin{array}{c}\text { Exposure } \\
\text { ascertainment }\end{array}$ & $\begin{array}{l}\text { Outcome } \\
\text { assessment }\end{array}$ & $\begin{array}{l}\text { Exposure } v s . \\
\text { comparison }\end{array}$ & $\begin{array}{l}\text { Risk estimates } \\
\text { and } 95 \% \text { CI }\end{array}$ & $\operatorname{Stars}^{11}$ \\
\hline Luo, 2012 & Cohort & $\mathrm{USA} ; \mathrm{HB}^{2}$ & $1993-2010$ & $\begin{array}{l}\text { Self-reported } \\
\text { on interview }\end{array}$ & ICD-O code 5 & Metformin vs. non & $1.32(0.76-2.28)$ & 7 \\
\hline Bodmer, 2012 & $\mathrm{C}-\mathrm{C} 1$ & $\mathrm{UK} ; \mathrm{PB}^{3}$ & $1995-2009$ & $\mathrm{GPRD}^{4}$ & $\begin{array}{l}\text { medical READ } \\
\text { codes }\end{array}$ & $\begin{array}{l}\text { Metformin vs. non } \\
\text { SUs }{ }^{6} \text { vs. non } \\
\text { Insulins vs. non }\end{array}$ & $\begin{array}{l}1.15(1.02-1.31) \\
0.96(0.85-1.09) \\
1.44(1.22-1.71)\end{array}$ & $\begin{array}{l}9 \\
9 \\
9\end{array}$ \\
\hline \multirow[t]{4}{*}{ Chang, 2012} & Cohort & Taiwan; PB & $2000-2007$ & Pharmacy & $\begin{array}{c}\text { NR9 } \\
\text { database }\end{array}$ & Metformin vs. non & $1.08(0.90-1.30)$ & 9 \\
\hline & & & & & & SUs vs. non & $0.89(0.74-1.08)$ & 9 \\
\hline & & & & & & Insulins vs. non & $1.86(1.56-2.23)$ & 9 \\
\hline & & & & & & TZDs $^{7}$ vs. non & $0.94(0.70-1.27)$ & 9 \\
\hline \multirow[t]{2}{*}{ Mazzone, 2012} & $\mathrm{C}-\mathrm{C}$ & USA;HB & $1978-2010$ & $\begin{array}{l}\text { Electronic medical records } \\
\text { of the Cleveland Clinic }\end{array}$ & NR & Metformin vs. non & $1.47(1.12-1.92)$ & 6 \\
\hline & & & & & & TZDs vs. non & $1.04(0.65-1.66)$ & 6 \\
\hline Hsieh, 2012 & Cohort & Taiwan; PB & $2000-2008$ & NHIRD $^{8}$ & ICD-9 & $\begin{array}{l}\text { Insulins vs. Metformin } \\
\text { SUs vs. Metformin }\end{array}$ & $\begin{array}{l}1.058(0.513-2.183) \\
1.570(1.110-2.220)\end{array}$ & $\begin{array}{l}7 \\
7\end{array}$ \\
\hline Ferrara, 2011 & Cohort & USA; HB & $1997-2005$ & Pharmacy & $\begin{array}{c}\mathrm{NR} \\
\text { database }\end{array}$ & Pioglitazone vs. non & $1.04(0.85-1.27)$ & 7 \\
\hline Govindarajan, 2006 & Cohort & USA; HB & $1997-2004$ & electronic record ${ }^{10}$ & ICD-9 & TZDs vs. non & $0.67(0.51-0.87)$ & 7 \\
\hline Kao, 2012 & Cohort & Taiwan; PB & 2001-2009 & NHIRD & NR & TZDs vs. non & $1.11(0.63-1.95)$ & 9 \\
\hline Van Staa, 2011 & Cohort & $\mathrm{UK} ; \mathrm{PB}$ & $1997-2006$ & GPRD & ICD-10 & $\begin{array}{l}\text { Metformin vs. non } \\
\text { SUs vs. non } \\
\text { Insulins vs. non } \\
\text { TZDs vs. non }\end{array}$ & $\begin{array}{l}0.89(0.76-1.03) \\
0.71(0.61-0.84) \\
0.63(0.47-0.84) \\
1.29(0.91-1.83)\end{array}$ & $\begin{array}{l}9 \\
9 \\
9 \\
9\end{array}$ \\
\hline $\mathrm{Gu}, 2012$ & Cohort & China:PB & 2001-2011 & $\begin{array}{c}\text { Shanghai Diabetes } \\
\text { Registry (SDR) } \\
\text { database }\end{array}$ & ICD-9, ICD-10 & Insulins vs. non & $1.00(0.46-2.17)$ & 7 \\
\hline Ruiter, 2011 & Cohort & Netherlands; PB & $1998-2008$ & The drug-dispensing database & ICD-9 & Metformin vs. SUs & $0.87(0.84-0.91)$ & 7 \\
\hline Wang, 2013 & $\mathrm{C}-\mathrm{C}$ & Taiwan; PB & $1998-2009$ & NHIRD & ICD-9 & Metformin vs. non & $1.11(0.94-1.47)$ & 7 \\
\hline Libby, 2009 & Cohort & $\mathrm{UK} ; \mathrm{PB}$ & 1994-2003 & $\begin{array}{c}\text { A pharmacoepidemiological } \\
\text { database }\end{array}$ & ICD9, ICD10 & Metformin vs. non & $0.70(0.43-1.15)$ & 9 \\
\hline \multirow[t]{4}{*}{ Lai, 2011} & Cohort & Taiwan; PB & $2000-2008$ & $\begin{array}{l}\text { the National Health } \\
\text { Research Institutes }\end{array}$ & ICD-9 & Insulins vs. non & $1.00(0.68-1.45)$ & 7 \\
\hline & & & & & & Metformin vs. non & $0.55(0.37-0.82)$ & 7 \\
\hline & & & & & & SUs vs. non & $1.27(0.75-2.15)$ & 7 \\
\hline & & & & & & TZDs vs. non & $0.55(0.32-0.94)$ & 7 \\
\hline Smiechowski, 2012 & $\mathrm{C}-\mathrm{C}$ & $\mathrm{UK} ; \mathrm{PB}$ & $1988-2009$ & GPRD & $\begin{array}{l}\text { Read diagnostic } \\
\text { codes }\end{array}$ & Metformin vs. non & $0.94(0.76-1.17)$ & 7 \\
\hline
\end{tabular}

C-C: case-control; HB: Hospital-based; PB: Population-based; GPRD: the General Practice Research Database; ICD: International Classification of Diseases; SUs: Sulfonylureas;TZDs: thiazolidinediones; NHIRD: the National Health Insurance Research Database; NR: not reported; electronic record :an electronic database covering 10 Veterans' Affairs (VA) hospitals; Stars (maximum=9) indicate the quality of the studies assessed using the Newcastle-Ottawa Scale 


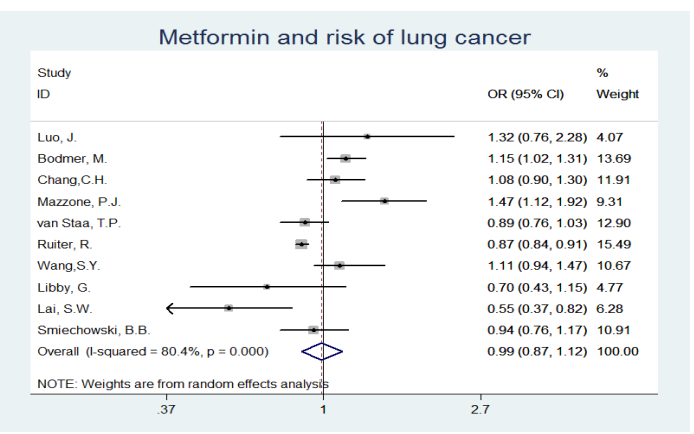

Figure 2. Random Effects Meta-Analysis of The Association between Metformin and Lung Cancer.

Table 2. Subgroup Analysis for ADMs and Lung Cancer

\begin{tabular}{|c|c|c|c|}
\hline Subgroups & No. of studies & Adjusted OR & $95 \% \mathrm{CI}$ \\
\hline \multicolumn{4}{|l|}{ Metformin } \\
\hline \multicolumn{4}{|l|}{ Study design } \\
\hline Cohort & 6 & 0.89 & $0.77-1.02$ \\
\hline $\mathrm{C}-\mathrm{C}$ & 4 & 1.14 & $0.98-1.32$ \\
\hline \multicolumn{4}{|l|}{ Study setting } \\
\hline Hospital based & 2 & 1.44 & $1.13-1.83$ \\
\hline Population based & 8 & 0.94 & $0.83-1.06$ \\
\hline \multicolumn{4}{|l|}{ Study location } \\
\hline Asia & 3 & 0.91 & $0.66-1.27$ \\
\hline Europe & 5 & 0.94 & $0.82-1.07$ \\
\hline USA & 2 & 1.44 & $1.13-1.83$ \\
\hline \multicolumn{4}{|l|}{ Sulfonylureas } \\
\hline \multicolumn{4}{|l|}{ Study design } \\
\hline Cohort & 4 & 1.01 & $0.73-1.41$ \\
\hline $\mathrm{C}-\mathrm{C}$ & 1 & 0.96 & 0.85-1.09 \\
\hline \multicolumn{4}{|l|}{ Study setting } \\
\hline Hospital based & 0 & & \\
\hline Population based & 5 & 0.98 & $0.79-1.22$ \\
\hline \multicolumn{4}{|l|}{ Study location } \\
\hline Asia & 3 & 1.18 & $0.79-1.76$ \\
\hline Europe & 2 & 0.83 & $0.62-1.11$ \\
\hline USA & 0 & & \\
\hline \multicolumn{4}{|l|}{ Insulin } \\
\hline \multicolumn{4}{|l|}{ Study design } \\
\hline Cohort & 5 & 1.05 & $0.62-1.80$ \\
\hline $\mathrm{C}-\mathrm{C}$ & 1 & 1.44 & $1.22-1.70$ \\
\hline \multicolumn{4}{|l|}{ Study setting } \\
\hline Hospital based & 0 & & \\
\hline Population based & 6 & 1.13 & $0.79-1.62$ \\
\hline \multicolumn{4}{|l|}{ Study location } \\
\hline Asia & 4 & 1.26 & $0.82-1.94$ \\
\hline Europe & 2 & 0.96 & $0.43-2.16$ \\
\hline USA & 0 & & \\
\hline \multicolumn{4}{|l|}{ Thiazolidinediones } \\
\hline \multicolumn{4}{|l|}{ Study design } \\
\hline Cohort & 6 & 0.91 & $0.72-1.14$ \\
\hline $\mathrm{C}-\mathrm{C}$ & 1 & 1.04 & $0.65-1.66$ \\
\hline \multicolumn{4}{|l|}{ Study setting } \\
\hline Hospital based & 2 & 0.84 & $0.55-1.30$ \\
\hline Population based & 5 & 0.98 & $0.76-1.26$ \\
\hline \multicolumn{4}{|l|}{ Study location } \\
\hline Asia & 3 & 0.85 & $0.59-1.21$ \\
\hline Europe & 3 & 0.89 & $0.65-1.22$ \\
\hline USA & 1 & 1.29 & $0.91-1.83$ \\
\hline
\end{tabular}

1. The earliest study period began in 1993 and the latest ended in 2011. Of the 15 studies, 11 (Govindarajan et al.,

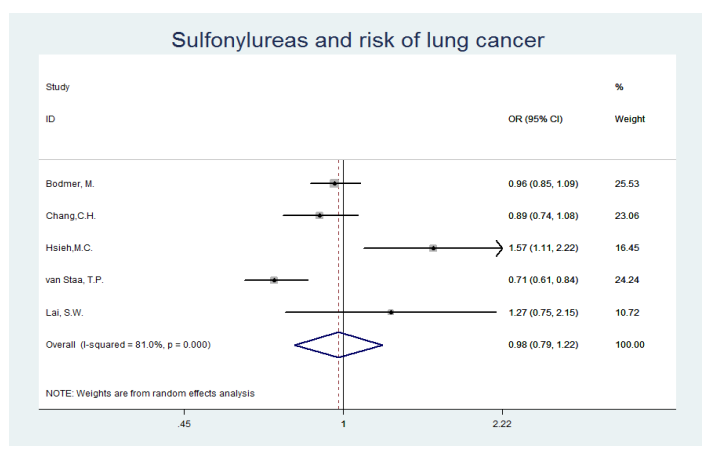

Figure 3. Random Effects Meta-Analysis of the Association between SUs and Lung Cancer; SUs=sulfonylureas

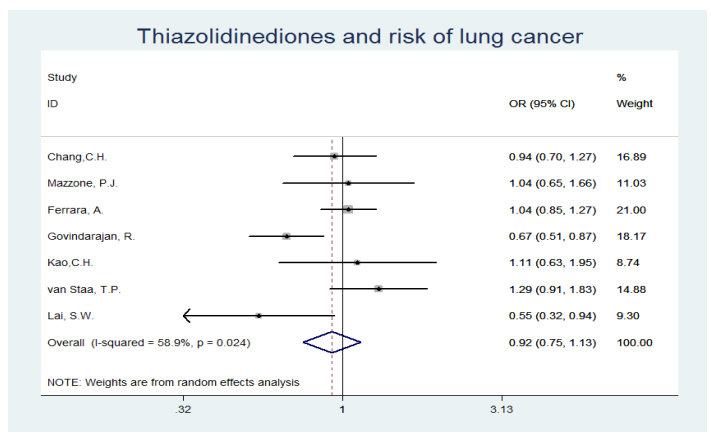

Figure 4. Random Effects Meta-Analysis of the Association between TZDs and Lung Cancer; TZDs =thiazolidinediones

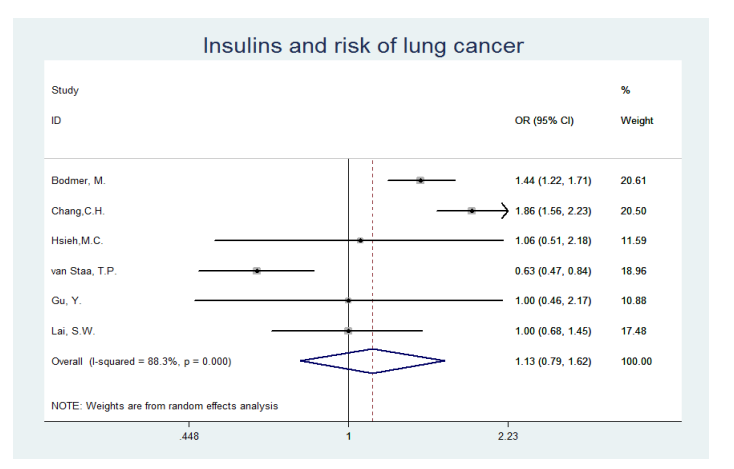

Figure 5. Random effects Meta-Analysis of the Association between Insulin and Lung Cancer.

2007; Lai et al., 2009; Ferrara et al., 2011; Chang et al., 2012; Hsieh et al., 2012; Luo et al., 2012; Ruiter et al., 2012; van Staa et al., 2012; Gu et al., 2013; Kao et al., 2013) were cohort studies and the other four (Bodmer, 2012; Mazzone et al., 2012; Smiechowski et al., 2013; Wang et al., 2013) were case-control studies. 11 of these studies were population-based studies (Libby et al., 2009; Bodmer, 2012; Chang et al., 2012; Hsieh et al., 2012; Lai et al., 2012; Ruiter et al., 2012; van Staa et al., 2012; Gu et al., 2013; Kao et al., 2013; Smiechowski et al., 2013; Wang et al., 2013), and the remainders were hospital-based studies (Govindarajan et al., 2007; Ferrara et al., 2011; Luo et al., 2012; Mazzone et al., 2012). Of the total studies, six were from Europe and five were from Asian and the remaining four were from USA. 
Quantitative Synthesis and Test of Heterogeneity

(1) Metformin and risk of lung cancer

On meta-analysis of all observational studies assessing the risk of lung cancer in patients with DM, use of metformin (as compared with non-use) did not show a significant association with lung cancer in patients with DM ( $n=11$ studies; adjusted OR=0.99, 95\%CI: 0.87 $1.12)$, and this was stable across different study designs (Figure 2 ). Significant study heterogeneity $\left(I^{2}=80.4 \%\right)$ was found, so a random effects model was used to pool the ORs. In sub-group analysis, almost no statistically significant results were detected. In subgroup analysis for study setting, two studies (Luo et al., 2012; Mazzone et al., 2012) were hospital-based studies, and the SRR was 1.44 (1.13-1.83). In analysis for study location, the same two studies were from USA and the SRR was the same. The sub-group analysis for ADMs and lung cancer was shown in Table 2.

(2) Sulfonylureas and risk of lung cancer

Meta-analysis of five observational studies that evaluated the risk of lung cancer associated with SUs exposure in patients with DM demonstrated no significant protective or harmful effect (adjusted $\mathrm{OR}=0.98,95 \% \mathrm{CI}$ : $0.79-1.22$ ) (Figure 3). There was statistically heterogeneity $\left(I^{2}=81.0 \%\right)$ among studies, so a random effects model was used to pool the ORs.

(3) Thiazolidinediones and risk of lung cancer

Use of TZDs (as compared with non-use) was not associated with significant increase in the risk of lung cancer in patients with DM ( $n=7$ studies; adjusted $\mathrm{OR}=0.92,95 \% \mathrm{CI}: 0.75-1.13)$ in observational studies (Figure 4). Significant study heterogeneity $\left(I^{2}=58.9 \%\right)$ was found, so a random effects model was used to pool the ORs.

(4) Insulin and risk of lung cancer

Use of insulin (as compared with non-use) was not associated with significant increase in the risk of lung cancer in patients with DM ( $\mathrm{n}=6$ studies; adjusted $\mathrm{OR}=1.13$, 95\%CI: 0.79-1.62) in observational studies (Figure 5). There was statistically heterogeneity $\left(I^{2}=88.3 \%\right)$ among studies, so a random effects model was used to pool the ORs.

\section{Exploration of the sources of heterogeneity}

As seen above, strong heterogeneity among studies on ADMs and lung cancer was demonstrated. To further explore the potential sources of heterogeneity and test the effects of study characteristics on the overall estimates, exploratory univariate meta-regression was performed with study-location (Asia , Europe and USA), source of controls (PB or HB) and study design (cohort or case-control study). However, none of the variables was identified as potentially important source of between-study heterogeneity.

\section{Sensitivity analysis and publication bias}

The influence of each study on the pooled ORs was examined by repeating the meta-analysis while sequentially omitting individual studies. In the sensitivity analysis, no individual study substantially influenced the pooled ORs for all the ADMs, suggesting that the results
Antidiabetic Medications and Lung Cancer Risk in DM Sufferers

of our meta-analysis are stable.

We plotted Begg's funnel plot to examine small study effects. We also used Begg's and Egger's weighted regression method to calculate $\mathrm{P}$ for bias. There was no evidence of significant publication bias, both quantitatively ( $p=0.223$ for metformin, $p=0.357$ for SUs, $p=0.297$ for TZDs, and $p=0.818$ for insulin) and qualitatively, on visual inspection of the funnel plot (data not shown).

\section{Discussion}

In this meta-analysis of 15 studies analyzing the effect of conventional ADMs on modifying the risk of lung cancer in patients with DM, we found that metformin use was not associated with a decreased risk of lung cancer, though there was a slight trend towards lower risk. Likewise, the other three ADMs (SUs and TZDs, insulin) use were not associated with an increased risk of lung cancer. There was, however, considerable heterogeneity across all studies that could not be explained by study design, setting, or location.

A series of studies and meta-analyses have shown an increased risk of cancer in DM patients (Yang et al., 2013; Tong et al., 2014). In particular, meta-analyses have revealed a strong association between diabetes and cancers of the pancreas or liver, the main organs implicated during the deregulation of the metabolic equilibrium that is typical in DM (Vigneri et al., 2009). Altered metabolic pathologies, such as hyperglycemia and hyperinsulinemia, as well as other DM-associated factors, such as obesity and high saturated fat diets, are also independent risk factors for cancer, illustrating a close correlation between the two diseases (Jalving et al., 2010). And several studies have suggested the use of metformin as an anticancer drug, but some limitations need to be considered.

Preclinical studies have suggested that ADMs may modify the risk of cancer. Although the exact molecular mechanisms of this protective effect remain unclear, it has been postulated that metformin may retard cellular neoplasia via its impact on AMPK metabolism. And AMPK could be activated by metformin via the following three independent mechanisms: (1) by LKB1 (liver kinase B1), which induces phosphorylation of Thr 172 in the catalytic subunit of AMPK (Long et al., 2006); (2) indirectly through the inhibition of complex I of the respiratory chain; and (3) by the activation of other inhibitors of mitochondrial ATP synthesis, such as oligomycin. On the other hand, SUs, by increasing insulin secretion, and insulin, itself, can promote carcinogenesis either directly or indirectly by increasing insulin-like growth factor-1 activity, resulting in abnormal stimulation of multiple cellular signaling cascades, enhancing growth factor-dependent cell proliferation, and affecting cell metabolism (Bowker et al., 2006).

The strengths of our study is comprehensive and simultaneous assessment of the effects of all conventional ADMs on risk modification of lung cancer in patients with DM. Although Noto et al. (Noto et al., 2012) and Franciosi et al. (Franciosi et al., 2013) have reported, in two small meta-analyses, the effect of metformin on chemoprevention in lung cancer, this is the first study that 
systematically analyzes the effects of SUs, TZDs, and insulin on modifying the risk of lung cancer.

In addition, there are some limitations inherent to a meta-analysis of observational studies, especially when assessing the impact of ADMs. Firstly, observational studies lack the experimental random allocation of the intervention necessary to test exposure-outcome hypotheses optimally. Secondly, all studies did not adjust for the same confounders. In addition, most patients with DM in these studies were on multiple ADMs simultaneously. As a result, the nature of the comparator group for each individual ADM was composed of other ADMs that may have an inherent cancer- modifying effect. For example, as compared with patients on metformin, patients "not on metformin" (the comparator group) would be more likely to be on SUs. Therefore, it is difficult to interpret whether the risk modification inferred for any one agent is real or confounded by exposures to other glucose-lowering medications. In the only monotherapy population-based observational study which compared cancer incidence with metformin and SUs in patients with DM, Ruiter et al. (Ruiter et al., 2012) demonstrated that metformin use was associated with a $13 \%$ decrease in risk of lung cancer, as compared with SUs. Ideally, the true clinical effect of ADMs on cancer risk would be studied by comparing patients on medical therapy for DM and those managed by non-medical/dietary therapy, over an extended period of time.

Based on the results of this comprehensive metaanalysis, chemopreventive effects of the four AMDs on lung cancer are questionable. This question is difficult to address based on retrospective studies due to confounding by indication and reverse causality. A randomized trial assessing the effect of specific ADMs on the incidence of lung cancer would be hypothetically very difficult to realize because of the required sample size and duration of follow-up (Johnson et al., 2010). More prospective observational studies, which account for these sources of heterogeneity, would be required to truly assess the impact of ADMs on risk of lung cancer.

In conclusion, meta-analysis of existing studies does not support a protective or harmful association between ADMs use and risk of lung cancer in patients with DM. There was considerable heterogeneity across studies, and future, well-designed, prospective studies would be required to understand this association better.

\section{Acknowledgement}

This work was supported by National Natural Science Foundation of China (grants 81072358 and 81273151) The authors declare no competing interests.

\section{References}

Atchison EA, Gridley G, Carreon JD, Leitzmann MF, McGlynn KA (2011). Risk of cancer in a large cohort of U.S. Veterans with diabetes. Int J Cancer, 128, 635-43.

Awoniyi O, Rehman R, Dagogo-Jack S (2013). Hypoglycemia in patients with type 1 diabetes: Epidemiology, pathogenesis, and prevention. Curr Diab Rep, 13, 669-78.
Bach PB, Kattan MW, Thornquist MD, et al (2003). Variations in lung cancer risk among smokers. J Natl Cancer Inst, $\mathbf{9 5}$, 470-8.

Bodmer M (2012). Metformin does not alter the risk of lung cancer: A case-control analysis. Lung Cancer, 78, 133-7.

Bowker SL, Majumdar SR, Veugelers P, Johnson JA (2006). Increased Cancer-Related Mortality for Patients with Type 2 Diabetes Who Use Sulfonylureas or Insulin. Diabetes Care, 29, 254-8.

Bruske-Hohlfeld I (2009). Environmental and occupational risk factors for lung cancer. Methods $\mathrm{Mol} \mathrm{Biol,} \mathrm{472,} \mathrm{3-23.}$

Cassidy A, Myles JP, van Tongeren M, et al (2008). The LLP risk model: An individual risk prediction model for lung cancer. Br J Cancer, 98, 270-6.

Chang CH, Lin JW, Wu LC, Lai MS, Chuang LM (2012). Oral insulin secretagogues, insulin, and cancer risk in type 2 diabetes mellitus. J Clin Endocrinol Metab, 97, E1170-5.

Decensi A, Puntoni M, Goodwin P, et al (2010). Metformin and cancer risk in diabetic patients: A systematic review and meta-analysis. Cancer Prev Res (Phila), 3, 1451-61.

Ding J, Tang J, Chen X, et al (2013). Expression characteristics of proteins of the insulin-like growth factor axis in non-small cell lung cancer patients with preexisting type 2 diabetes mellitus. Asian Pac J Cancer Prev, 14, 5675-80.

Egger M, Davey SG, Schneider M, Minder C (1997). Bias in meta-analysis detected by a simple, graphical test. $B M J$, 315, 629-34.

Ehrlich SF, Quesenberry CJ, Van Den Eeden SK, Shan J, Ferrara A (2010). Patients diagnosed with diabetes are at increased risk for asthma, chronic obstructive pulmonary disease, pulmonary fibrosis, and pneumonia but not lung cancer. Diabetes Care, 33, 55-60.

Ferrara A, Lewis JD, Quesenberry CJ, et al (2011). Cohort study of pioglitazone and cancer incidence in patients with diabetes. Diabetes Care, 34, 923-9.

Franciosi M, Lucisano G, Lapice E, et al (2013). Metformin therapy and risk of cancer in patients with type 2 diabetes: Systematic review. PLoS One, 8, 71583.

Gallagher EJ, LeRoith D (2011). Diabetes, cancer, and metformin: Connections of metabolism and cell proliferation. Ann $N Y$ Acad Sci, 1243, 54-68.

Gao Y, Goldstein AM, Consonni D, etal (2009). Family history of cancer and nonmalignant lung $\mathrm{d}$ iseases as risk factors for lung cancer. Int J Cancer, 125, 146-52.

Govindarajan R, Ratnasinghe L, Simmons DL, et al (2007). Thiazolidinediones and the risk of lung, prostate, and colon cancer in patients with diabetes. J Clin Oncol, 25, 1476-81.

Gu Y, Wang C, Zheng Y, et al (2013). Cancer incidence and mortality in patients with type 2 diabetes treated with human insulin: A cohort study in Shanghai. PLoS One, 8, 53411.

Hall GC, Roberts CM, Boulis M, Mo J, MacRae KD (2005). Diabetes and the risk of lung cancer. Diabetes Care, 28, 590-4.

Higgins JP, Thompson SG, Deeks JJ, Altman DG (2003). Measuring inconsistency in meta-analyses. BMJ, 327, 557-60.

Hsieh MC, Lee TC, Cheng SM, et al (2012). The influence of type 2 diabetes and glucose-lowering therapies on cancer risk in the Taiwanese. Exp Diabetes Res, 2012, 413782.

Jalving M, Gietema JA, Lefrandt JD, et al (2010). Metformin: Taking away the candy for cancer? Eur J Cancer, 46, 2369-80.

Jemal A, Siegel R, Xu J, Ward E (2010). Cancer statistics, 2010. CA Cancer J Clin, 60, 277-300.

Johnson JA, Yasui Y (2010). Glucose-lowering therapies and cancer risk: The trials and tribulations of trials and observations. Diabetologia, 53, 1823-6. 
Kao CH, Sun LM, Chen PC, et al (2013). A population-based cohort study in Taiwan--use of insulin sensitizers can decrease cancer risk in diabetic patients? Ann Oncol, 24, 523-30.

Lai SW, Liao KF, Chen PC, et al (2012). Antidiabetes drugs correlate with decreased risk of lung cancer: A populationbased observation in Taiwan. Clin Lung Cancer, 13, 143-8.

Lam WK, White NW, Chan-Yeung MM (2004). Lung cancer epidemiology and risk factors in Asia and Africa. Int J Tuberc Lung Dis, 8, 1045-57.

Leone A, Di Gennaro E, Bruzzese F, Avallone A, Budillon A (2014). New perspective for an old antidiabetic drug: Metformin as anticancer agent. Cancer Treat Res, 159, 355-76.

Libby G, Donnelly LA, Donnan PT, et al (2009). New users of metformin are at low risk of incident cancer: A cohort study among people with type 2 diabetes. Diabetes Care, 32, $1620-5$.

Long YC, Zierath JR (2006). AMP-activated protein kinase signaling in metabolic regulation. J Clin Invest, 116, 177683.

Luo J, Chlebowski R, Wactawski-Wende J, et al (2012). Diabetes and lung cancer among postmenopausal women. Diabetes Care, 35, 1485-91.

Mazzone PJ, Rai H, Beukemann M, Xu M, Jain A, Sasidhar M (2012). The effect of metformin and thiazolidinedione use on lung cancer in diabetics. Bmc Cancer, 12, 410.

Mulshine JL, Sullivan DC (2005). Clinical practice. Lung cancer screening. N Engl J Med, 352, 2714-20.

Noto H, Goto A, Tsujimoto T, Noda M (2012). Cancer risk in diabetic patients treated with metformin: A systematic review and meta-analysis. PLoS One, 7, 33411.

Ogunleye AA, Ogston SA, Morris AD, Evans JM (2009). A cohort study of the risk of cancer associated with type 2 diabetes. Br J Cancer, 101, 1199-201.

Okumura T (2010). Mechanisms by which thiazolidinediones induce anti-cancer effects in cancers in digestive organs. $J$ Gastroenterol, 45, 1097-102.

Rousseau M, Parent M, Pollak MN, Siemiatycki J (2006). Diabetes mellitus and cancer risk in a population-based case-controlstudy among men from Montreal, Canada. Int J Cancer, 118, 2105-9.

Ruano-Ravina A, Figureueiras A, Barros-Dios JM (2003). Lung cancer and related risk factors: An update of the literature. Public Health, 117, 149-56.

Ruiter R, Visser LE, van Herk-Sukel MP, et al (2012). Lower risk of cancer in patients on metformin in comparison with those on sulfonylurea derivatives: Results from a large populationbased follow-up study. Diabetes Care, 35, 119-24.

Smiechowski BB, Azoulay L, Yin H, Pollak MN, Suissa S (2013). The use of metformin and the incidence of lung cancer in patients with type 2 diabetes. Diabetes Care, $\mathbf{3 6}$, 124-9.

Soranna D, Scotti L, Zambon A, et al (2012). Cancer risk associated with use of metformin and sulfonylurea in type 2 diabetes: A meta-analysis. Oncologist, 17, 813-22.

Spitz MR, Hong WK, Amos CI, et al (2007). A risk model for prediction of lung cancer. J Natl Cancer Inst, 99, 715-26.

Staimez LR, Weber MB, Narayan KM, Oza-Frank R (2013). A systematic review of overweight, obesity, and type 2 diabetes among Asian American subgroups. Curr Diabetes $\operatorname{Rev}, \mathbf{9}, 312-31$.

Tammemagi CM, Pinsky PF, Caporaso NE, et al (2011). Lung cancer risk prediction: Prostate, Lung, Colorectal and Ovarian Cancer Screening Trial models and validation. $J$ Natl Cancer Inst, 103, 1058-68.

Tobias A (1999). Assessing the influence of a single study in the meta-analysis estimate.15-7.

Tong GX, Cheng J, Chai J, et al (2014). Association between gestational diabetes mellitus and subsequent risk of cancer: A systematic review of epidemiological studies. Asian Pac J Cancer Prev, 15, 4265-9.

Tyczynski JE, Bray F, Parkin DM (2003). Lung cancer in Europe in 2000: Epidemiology, prevention, and early detection. Lancet Oncol, 4, 45-55.

van Staa TP, Patel D, Gallagher AM, de Bruin ML (2012). Glucose-lowering agents and the patterns of risk for cancer: A study with the General Practice Research Database and secondary care data. Diabetologia, 55, 654-65.

Vigneri P, Frasca F, Sciacca L, Pandini G, Vigneri R (2009). Diabetes and cancer. Endocr Relat Cancer, 16, 1103-23.

Wang SY, Chuang CS, Muo CH, et al (2013). Metformin and the incidence of cancer in patients with diabetes: A nested case-control study. Diabetes Care, 36, e155-6.

Wells GA, Shea B, O'Connell D, et al (2013). The NewcastleOttawa Scale (NOS) for assessing the quality of nonrandomized studies in meta-analyses.http://www.ohri. ca/programs/clinical_epidemiology/oxford.asp. Accessed April 3, 2013.

Wu CY, Hu HY, Pu CY, Huang N, Shen HC, Li CP, Chou YJ (2011). Pulmonary tuberculosis increases the risk of lung cancer: A population-based cohort study. Cancer, 117, 618-24.

Yang X, Xu C, Sun Y, Han R (2013). Diabetes mellitus increases the risk of bladder cancer: An updated meta-analysis. Asian Pac J Cancer Prev, 14, 2583-9.

Zabetian A, Keli HM, Echouffo-Tcheugui JB, Narayan KM, Ali MK (2013). Diabetes in the middle east and north africa. Diabetes Res Clin Pract, 101, 106-22. 